\title{
La participación ciudadana en el proceso del presupuesto participativo en la gestión municipal de Canchaque-Huancabamba
}

Citizen participation in the participatory budget process in the municipal management of Canchaque-Huancabamba

1 Fidel Antonio Ramírez Vidarte Universidad Cesar Vallejo, Piura, Perú p2000067191@ucvvirtual.edu.pe

2 Cecilia Teresita de Jesús Carbajal Llauce Universidad Cesar Vallejo, Piura, Perú cllaucect@ucvvirtual.edu.pe

3 Juan José Jacinto Chunga Universidad Nacional de Piura, Piura, Perú jjacinto@unp.edu.pe
iD https://orcid.org/0000-0001-6884-0020

https://orcid.org/0000-0002-1162-8755

https://orcid.org/0000-0002-8238-8947

Artículo de Investigación Científica y Tecnológica

Enviado: 09/12/2021

Revisado: $24 / 12 / 2021$

Aceptado: $28 / 01 / 2022$

Publicado:05/02/2022

DOI: https://doi.org/10.33262/ap.v4i1.1.156

participación ciudadana en el proceso del presupuesto participativo en la gestión municipal

Cítese: de Canchaque-Huancabamba. AlfaPublicaciones, 4(1.1), 223-254. https://doi.org/10.33262/ap.v4i1.1.156

ALFA PUBLICACIONES, es una Revista Multidisciplinar, Trimestral, que se publicará en soporte electrónico tiene como misión contribuir a la formación de profesionales competentes con visión humanística y crítica que sean capaces de exponer sus resultados investigativos y científicos en la misma medida que se promueva mediante su intervención cambios positivos en la sociedad. https://alfapublicaciones.com La revista es editada por la Editorial Ciencia Digital (Editorial de prestigio registrada en la Cámara Ecuatoriana de Libro con No de Afiliación 663) www.celibro.org.ec

Esta revista está protegida bajo una licencia Creative Commons Attribution Non Commercial No Derivatives 4.0 International. Copia de la licencia: http://creativecommons.org/licenses/by-nc-nd/4.0/ 
Palabras

claves:

participación

ciudadana,

presupuesto

participativo,

gestión

municipal

\section{Resumen}

El estudio plantea como objetivo general diseñar un plan con participación ciudadana para orientar el presupuesto participativo en la gestión del municipio de Canchaque - Huancabamba. Se aplicó una metodología básica, descriptiva no experimental. Los resultados obtenidos permitieron concluir que, a partir del análisis y relación de ambas variables, se estableció, la necesidad de establecer un conjunto de estrategias tales como realizar seguimientos a los proyectos de obras públicas, organizar reuniones periódicas, diseñar el reglamento, crear un canal de comunicación móvil, un plan de trabajo, aplicar auditorías y la creación de comités de seguimiento. Para ello. Se plantea un conjunto de medios de verificación tales como las actas de reuniones, grabación audiovisual, informes de auditoría, resoluciones municipales e informes de monitoreo. De igual manera se plantea un cronograma acorde al planteamiento de las estrategias del plan las mismas que van desde una, dos meses, durante un mes, cada dos meses y durante todo un periodo de gobierno edil. Finalmente, se establece que recursos deben tomarse en cuenta entre ellos los libros de actas, el registro de asistencia, las fichas de verificación, el libro de auditorías y las fichas de registro.

\begin{tabular}{ll}
\hline Keywords: & Abstract \\
citizen & The general objective of the study is to design a plan with citizen \\
participation, & participation to guide the participatory budget in the management \\
participatory & of the municipality of Canchaque - Huancabamba. A basic, non- \\
budget, & experimental descriptive methodology was applied. The results \\
municipal & obtained allowed us to conclude that from the analysis and \\
management & relationship of both variables, the need to establish a set of strategies \\
& such as monitoring public works projects, organizing regular \\
& meetings, designing regulations, creating a communication channel \\
& was established. mobile communication, a work plan, apply audits \\
& and the creation of monitoring committees. For it. A set of means \\
& of verification is proposed, such as the minutes of meetings, \\
& audiovisual recording, audit reports, municipal resolutions and \\
& monitoring reports. In the same way, a schedule is proposed \\
& according to the approach of the strategies of the plan, which range \\
& from one, two months, for one month, every two months and for an \\
& entire period of municipal government. Finally, it is established \\
& which resources must be taken into account, among them the minute \\
\hline
\end{tabular}

\section{Keywords:}

budget, municipa 
books, the attendance record, the verification sheets, the audit book and the registration sheets.

\section{Introducción}

América Latina y sus procesos democráticos ha permitido a lo largo de los años que los ciudadanos tengan un papel más protagónico y participativo, permitiendo que la sociedad unida, puedan tomar decisiones en cuanto a procesos de gestión de presupuesto, y acciones en pro de su beneficio.

Desde la experiencia de la política latinoamericana la participación social del presupuesto edil, surge como consecuencia de los problemas de gobernabilidad y corrupción en diversas naciones, en donde a propuesta de Naciones Unidas introduce la necesidad de corregir la gobernabilidad, enfrentar la corrupción, el transparentar los gastos y la rendición de cuentas (Buele-Nugra \& Vidueira, 2018). En este sentido se menciona que la participación ciudadana se ha notado en la actividad gubernamental que a su vez se encuentra amparado en las Constituciones establecidas en cada país (Núñez \& Pedroza, 2019).

Sin embargo, esta participación no es del todo completa, o considerada real, pues existen fallas ya que ocurre que algunos funcionarios públicos no tienen el apoyo de su pueblo, lo que genera un obstáculo para que la sociedad le apoye o en su defecto el gobierno local no desea que exista esta participación ciudadana (Montecinos \& Contreras, 2019).

Asimismo, se menciona que la participación ciudadana en Perú no ha sido muy activa en los últimos años, de manera que la Contraloría de la República asegura que esto ha generado que existan mayores niveles de corrupción por que los ciudadanos consideran que no es un asunto de interés. En base a lo antes mencionado Llona (2017), define la participación ciudadana como un involucramiento de los ciudadanos en los aspectos públicos de su comunidad, esto es logrado con diversos mecanismos para que se efectué esta participación, y esta participación surge de la búsqueda de integrar los problemas sociales con el estado, pues mas allá de solo participar, este procesos permite la interacción entre los diversos actores políticos y sociales existentes que les permitirá crear los objetivos y las metas necesarias para cumplir tal fin.

En este sentido Canto (2017) expresa que, en una democracia participativa, el gobierno debe involucrar a la colectividad para asegurar la redistribución del poder en un contexto de pluralidad democrática.

En otras palabras, son los ciudadanos quienes se involucran activamente en las decisiones públicas; no obstante, el Estado no le ha dado mucha importancia y por ende ha generado 
una disconformidad por parte de la sociedad. Así mismo, en la promoción de la participación pública, el gobierno local se desliga de la presión que pueda tener de los ciudadanos porque se da oportunidad a los ciudadanos de expresar sus puntos de vista, ideas y preocupaciones, y donde al final toma decisiones para resolver los problemas vecinales (Maurice et al., 2019).

Respecto a las dimensiones de la participación vecinal, de acuerdo a los datos documentales destacan tres aspectos: La Política ciudadana, el aspecto cultural y el aspecto social. La política de participación ciudadana responde a un conjunto de mecanismos donde se involucran los derechos políticos, la responsabilidad y la representación ciudadana con el objetivo de fortalecer la legitimidad, la confianza, el ser transparente y el dar con claridad el nivel de gastos (Maurice et al., 2019).

En torno a la democracia voluntaria, participativa y universal esta también el presupuesto participativo donde la sociedad es capaz de discutir y poder decidir acerca del presupuesto y las políticas públicas, lo que demuestra que el pueblo no solo se limita a elegir a sus gobernantes a través de sus votos, sino también a través de decisiones sobre el gasto, la inversión, los recursos y el control de la actividad financiera del sector público (Príncipe et al., 2021)

De esta manera, Príncipe et al. (2021) señala que:

El presupuesto participativo es el mecanismo de gestión mediante el cual con un enfoque también participativo la municipalidad incorpora a la población organizada, para que, de manera concertada, determine el destino de una parte del presupuesto institucional a la ejecución de proyectos y obras de interés comunitario o vecinal. Con ese fin, la entidad debe determinar el monto destinado al proceso del presupuesto participativo, pero sin descuidar obligaciones propias, como los gastos operativos y de funcionamiento y los que correspondan a la atención de los servicios públicos locales. (p. 83)

Así mismo, el presupuesto participativo es un componente político que sirve para fortalecer la democracia representativa usando como medio el proceso anual presupuestario (González \& Soler, 2021).

El estudio plantea como objetivo general diseñar un plan con participación ciudadana para orientar el presupuesto participativo en la gestión del municipio de CanchaqueHuancabamba.

\section{Metodología}

Tipo y diseño de investigación 
La investigación se sustenta en una investigación básica, la cual se orienta a completar información teórica a través de la comprensión de los fenómenos y hechos que se pueden verificar o relacionarse entre sí a más de una variable (Consejo Nacional de Ciencia, Tecnología e Innovación Tecnológica [CONCYTEC], 2020).

También se escogió la tipología descriptiva propositiva, este tipo de investigación, parte del principio de identificar la necesidad y posteriormente establecer una solución a través de una propuesta (Hernández et al., 2010). Se ha seleccionado este tipo de investigación porque se busca plantear un plan de fortalecimiento y promoción de la intervención vecinal en cómo se debe distribuir el presupuesto en la instancia municipal.

Se trabaja con el diseño que no manipula variables como es no experimental. En el diseño no experimental se basa en un sistema de no manipulación de variables o categorías (Hernández et al., 2010). Se ha seleccionado este diseño porque recoge los datos de la participación de los vecinos y del presupuesto con participación comunitaria como componentes de diagnóstico para luego realizar una propuesta.

El diseño sobre el cual se realizó la investigación responde a lo siguiente:

\section{Figura1}

\section{Diagrama del diseño de investigación}

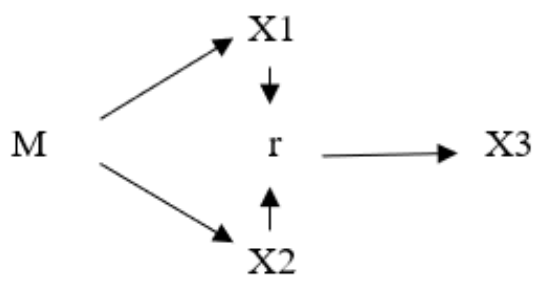

Nota: $\mathrm{M} \longrightarrow$ Muestra conformada por delegados de autoridades locales.

$\mathrm{X} 1 \longrightarrow$ Datos referentes a la participación ciudadana.

$\mathrm{X} 2 \longrightarrow$ Datos referidos al presupuesto participativo.

$\mathrm{r} \longrightarrow$ es la posible relación entre la participación ciudadana y presupuesto participativo

$\mathrm{X} 3 \longrightarrow$ Plan de fortalecimiento y promoción de la participación ciudadana en el proceso del presupuesto participativo. 
www.alfapublicaciones.com

Variables y operacionalización

- Variable Independiente: Participación ciudadana

- Variable dependiente: Presupuesto participativo

Esta operacionalizada en base a cuatro dimensiones ejecutar el presupuesto, beneficios de distribución, mecanismos planificados y concentrados, y resultados de etapa de ejecución de presupuestos.

Población, mиеstra y mиеstreo

-La población está conformada por 35 delegados y 05 autoridades

-Criterios de inclusión: se incluye aquellos delegados que tienen voluntad para trabajar, que siempre asisten a las reuniones y que tienen vocación de diálogo.

-Criterios de exclusión: se excluye aquellos ciudadanos que solo acuden de manera esporádica a las convocatorias y son responsables de sus decisiones.

Y queda expresado como se muestra en la tabla 1

Tabla 1

Distribución de la población

\begin{tabular}{llll}
\hline Sujetos & Sexo & Total \\
\cline { 2 - 3 } & Femenino & Masculino & \\
\hline Delegados & 05 & 30 & 35 \\
Autoridades & 02 & 03 & 05 \\
\hline Total & 07 & 33 & 40 \\
\hline
\end{tabular}

Nota: Base de datos registrada en secretaria de la Municipalidad de Canchaque

La muestra corresponde a una parte de la población escogida con características que se reproducen de forma exacta (Palella \& Martins, 2010).

La muestra de esta investigación, estuvo constituida por 25 delegados Se determinó mediante un muestreo de naturaleza no probabilística.

Tabla 2

Distribución de la muestra

\begin{tabular}{llll}
\hline Sujetos & \multicolumn{3}{c}{ Sexo } \\
Femenino & Masculino & Total \\
\hline Delegados & 03 & 17 & 20 \\
Autoridades & 01 & 04 & 05 \\
Total & 04 & 21 & 25 \\
\hline \multicolumn{4}{c}{ Nota: Base de datos registrada en secretaria de la } \\
\multicolumn{2}{c}{ Municipalidad de Canchaque }
\end{tabular}


Se decidió utilizar el muestreo no probabilístico de tipo por conveniencia el cual no es aleatorio y se determina por indicación de los objetivos. Se ha utilizado esta técnica de muestreo porque los seleccionados numéricamente son pocos.

Técnicas e instrumentos de recolección de datos

Como técnica se utiliza la encuesta, la cual es una técnica que se aplica a un grupo de personas un listado de enunciados o preguntas en un tiempo determinado (Palella \& Martins, 2010). Se ha seleccionado este tipo de técnica porque permite medir las percepciones de los sujetos de la investigación.

Se usará el cuestionario electrónico como instrumento para recoger los datos de la muestra. El cuestionario es un instrumento de investigación que forma parte de la técnica de la encuesta (Palella \& Martins. 2010). Se ha seleccionado este tipo de instrumento porque ayuda a recoger información sobre la percepción de las variables sobre participación de los ciudadanos en las decisiones presupuestales.

La validez permite que no existan sesgos, se refiere a la relación existente entre lo que se mide y lo que realmente se quiere medir, y esto permite garantizar su evidencia (Palella \& Martins, 2010). Para este procedimiento estadístico, se aplicó el método de validez por Juicio de especialistas con una total de 05 jueces.

La confiabilidad según indica Palella \& Martins (2010), es la ausencia de error aleatorio, por lo cual representa la influencia del azar en la medida. En este sentido en esta investigación se aplicó la prueba estadística Alfa de Cronbach para el cálculo de la confiabilidad, donde arrojó 0,919 del cuestionario participación ciudadana y 0,962 del cuestionario presupuesto participativo como se muestra en la tabla 3

\section{Tabla 3}

Estadísticas de fiabilidad

\begin{tabular}{lll}
\hline \multicolumn{1}{c}{ Variable } & Alfa de Cronbach & \multicolumn{1}{c}{$\begin{array}{c}\text { No de } \\
\text { elementos }\end{array}$} \\
\hline VI: Participación ciudadana & 0,919 & 25 \\
VD Presupuesto & 0,962 & 39 \\
participativo & & \\
\hline Nota: Prueba piloto & &
\end{tabular}

\section{Resultados y Discusión}

\section{Resultados descriptivos}

Objetivo específico 1.- Diagnosticar los niveles de incidencia de la participación ciudadana en la distribución del presupuesto municipal 
Tabla 4

Fases de participación ciudadana en el presupuesto municipal

\begin{tabular}{|c|c|c|c|c|c|c|}
\hline & & Totalmente & & $\mathrm{Ni}$ de & & \\
\hline N. ${ }^{\circ}$ & Ítems & $\begin{array}{c}\text { en } \\
\text { desacuerdo }\end{array}$ & $\begin{array}{c}\text { En } \\
\text { desacuerdo }\end{array}$ & $\begin{array}{l}\text { acuerdo ni } \\
\text { en } \\
\text { desacuerdo }\end{array}$ & $\begin{array}{c}\text { De } \\
\text { acuerdo }\end{array}$ & $\begin{array}{l}\text { Totalmente } \\
\text { de acuerdo }\end{array}$ \\
\hline
\end{tabular}

\begin{tabular}{llllllllll}
\hline $\mathrm{F}$ & $\%$ & $\mathrm{~F}$ & $\%$ & $\mathrm{~F}$ & $\%$ & $\mathrm{~F}$ & $\%$ & $\mathrm{~F}$ & $\%$
\end{tabular}

$01 \quad$ ¿El municipio respeta el diagnóstico de las necesidades de la

$\begin{array}{llllllllll}3 & 12,0 & 14 & 56,0 & 2 & 8,0 & 4 & 16,0 & 2 & 8,0\end{array}$

población que desean una obra pública para su sector?

02 ¿Considera Ud. que la ciudadanía participa en las distintas fases de la $\begin{array}{lllllllllll}\text { ejecución del presupuesto } & 4 & 16,0 & 13 & 52,0 & 1 & 4,0 & 5 & 20,0 & 2 & 8,0\end{array}$ participativo municipal?

03 ¿La información proporcionada por el municipio responde a los gastos ejecutados?

04 ¿Cuándo se produce una desavenencia en los compromisos $15 \quad 60,0 \quad 1 \quad 4,0$ $00 \quad 0,0$ $\begin{array}{lll}7 & 28,0 & 2\end{array}$ 8,0 municipales se resuelve escuchándose?

05 ¿Cuándo el municipio asume los compromisos, se retoma la participación para indicar los avances?

¿La ejecución de obras de importancia para el distrito mejora la calidad de vida de la población?

$\begin{array}{llllllllll}4 & 16,0 & 8 & 32,0 & 1 & 4,0 & 10 & 40,0 & 2 & 8,0\end{array}$

$\begin{array}{llllllllll}3 & 12,0 & 9 & 36,0 & 3 & 12,0 & 8 & 32,0 & 2 & 8,0\end{array}$

$\begin{array}{lllllllllll}\text { Total } & 5 & 20,0 & 10 & 40,0 & 2 & 8,0 & 6 & 24,0 & 2 & 8,0\end{array}$

Nota: Cuestionario aplicado a los integrantes de la muestra de estudio

En la tabla 4, de la dimensión fases de la participación ciudadana para decisiones presupuestales ediles, se observa que el $40 \%$ representado por 10 delegados de autoridades locales manifestaron estar en desacuerdo con el cumplimiento de estos ítems 
de dimensión, el 24\% representado por 6 encuestados están de acuerdo, el 20\% está en desacuerdo; el 8,0\% expresan estar ni de acuerdo ni en desacuerdo y también están totalmente de acuerdo, ambos de manera respectiva. Así mismo, el indicador con mayor incidencia en la decisión de estar totalmente en desacuerdo fue el referente a la desavenencia producidos por los compromisos municipales adquiridos por las autoridades ediles se resuelvan escuchándose, con el $60 \%$ representado por 15 delegados. Para el resto de los indicadores, se observa una tendencia de estar en desacuerdo, siendo en este caso el $56 \%$ representado por 14 representantes, la cifra es la misma para los indicadores primero de que el municipio respeta las necesidades de la población canalizándola en obra pública y segundo la información de los gastos ejecutados por obra pública es acorde con lo planificado; el 52\% representado por 13 encuestados está en desacuerdo de que la ciudadanía participe en las distintas fases de la ejecución presupuestal; en esa misma dirección el 36\% representado por 9 delegados indican que superada la desavenencia producido por el incumplimiento de los compromisos municipales sobre la ejecución de la obra, se continua con el avance de la misma: y el $32 \%$ representado por 8 delegados, de que la obra ejecutada en su zona mejore la calidad de vida de la población. Sobre este último ítem, el $40 \%$ representado por 10 delegados afirman estar de acuerdo a que si se mejora la calidad de vida de la población.

En el nivel de respuesta a los indicadores referidos a estar totalmente en desacuerdo los ítems 2 y 6 comparten el mismo porcentaje de $16 \%$ representado por 4 delegados; los ítems 1 , 3 y 5 comparten el mismo porcentaje de $12 \%$ representado por 3 encuestados. En el nivel de respuesta a los indicadores referidos a estar de acuerdo el ítem 6 registra el $40 \%$ representado por 10 personas, el ítem 5 con $32 \%$ representado por 8 personas, el ítem 4 con $28 \%$ representado por 7 personas; el ítem $220 \%$ representado por 5 delegados y los ítems 1 y 3 comparten el mismo porcentaje del16\% representado por 4 persona cada uno. En el nivel ni de acuerdo y de acuerdo, el ítem 5 es el de mayor porcentaje con el $12 \%$ representado por 3 delegados, los ítems 1 y 3 con $8 \%$ lo representan 2 personas cada uno y el ítem 6 con el $4 \%$ representado por 1 delegado. Por otro lado, en el nivel totalmente de acuerdo, todos los ítems están representados por el $8 \%$ representado por 2 delegados cada uno. 
Tabla 5

Mecanismos de participación ciudadana

\begin{tabular}{|c|c|c|c|c|c|c|c|c|c|c|c|}
\hline \multirow[t]{2}{*}{ N. ${ }^{o}$} & \multirow[t]{2}{*}{ Ítems } & \multicolumn{2}{|c|}{$\begin{array}{c}\text { Totalmente } \\
\text { en } \\
\text { desacuerdo }\end{array}$} & \multicolumn{2}{|c|}{$\begin{array}{c}\text { En } \\
\text { desacuerdo }\end{array}$} & \multicolumn{2}{|c|}{$\begin{array}{c}\text { Ni de } \\
\text { acuerdo ni } \\
\text { en } \\
\text { desacuerdo }\end{array}$} & \multicolumn{2}{|c|}{$\begin{array}{c}\text { De } \\
\text { acuerdo }\end{array}$} & \multicolumn{2}{|c|}{$\begin{array}{l}\text { Totalmente } \\
\text { de acuerdo }\end{array}$} \\
\hline & & $\mathrm{F}$ & $\%$ & $\mathrm{~F}$ & $\%$ & $\mathrm{~F}$ & $\%$ & $\mathrm{~F}$ & $\%$ & $\mathrm{~F}$ & $\%$ \\
\hline 01 & $\begin{array}{l}\text { ¿La población organizada } \\
\text { participa en la toma de } \\
\text { decisiones presupuestales del } \\
\text { municipio? }\end{array}$ & 2 & 8,0 & 7 & 28,0 & 8 & 32,0 & 5 & 20,0 & 3 & 12,0 \\
\hline 02 & $\begin{array}{l}\text { ¿La población organizada } \\
\text { efectiviza mejor la vigilancia } \\
\text { ciudadana sobre el gasto } \\
\text { municipal? }\end{array}$ & 14 & 56,0 & 1 & 4,0 & 0 & 0,0 & 8 & 32,0 & 2 & 8,0 \\
\hline 03 & $\begin{array}{l}\text { ¿Usted como representante } \\
\text { de la comunidad participa en } \\
\text { las audiencias de rendición } \\
\text { de cuentas de su comunidad? }\end{array}$ & 3 & 12,0 & 13 & 52,0 & 0 & 0,0 & 8 & 32,0 & 1 & 4,0 \\
\hline & Total & 6 & 24,0 & 7 & 28,0 & 3 & 12.0 & 7 & 28,0 & 2 & 8,0 \\
\hline
\end{tabular}

Nota: Cuestionario aplicado a los integrantes de la muestra de estudio

En la tabla 5, de la dimensión mecanismos de participación ciudadana para decisiones presupuestales ediles, se observa que el $28 \%$ representado por 7 delegados manifestaron estar en desacuerdo y en la misma proporción de acuerdo con el cumplimiento de estos ítems de dimensión, el 24\% representado por 6 encuestados están de acuerdo, el 20\% están totalmente en desacuerdo, el $12 \%$ representado por 3 delegados expresaron estar ni de acuerdo ni en desacuerdo, y el 8,0\% señalaron estar totalmente de acuerdo. Así mi smo, el indicador con mayor incidencia en la decisión de estar totalmente en desacuerdo fue el referente de que en una población organizada se efectiviza la vigilancia ciudadana sobre el gasto municipal, con el 56\% representado por 15 delegados, seguido del indicador 3 referido medir su nivel de participación en las audiencias de rendición de cuentas de su jurisdicción con la representación de un 52\% representado por 13 encuestados a los que respondieron con el desacuerdo. El resto de los indicadores mantiene cifras menores de respuesta. Así tenemos que el 32\% representado por 8 delegados comparten la misma respuesta con los ítems 2 y 3 y cada uno de ellos con un estar de acuerdo; el $28 \%$ representado por 7 personas del ítem 1señalaron estar en desacuerdo, el 12\% de los ítems 1 y 3 representado por 3 delegados cada uno, expresaron estar totalmente en acuerdo y también con la misma cifra estar en totalmente en desacuerdo, el $8 \%$ representado por 2 delegados refiriéndose del ítem 2 están totalmente de acuerdo; y el 4\% representado por 
1 solo delegado señalaron para el ítem 2 estar totalmente en desacuerdo, y para el ítem 3 estar totalmente de acuerdo.

\section{Tabla 6}

Ejecutar el presupuesto participativo

\begin{tabular}{|c|c|c|c|c|c|c|c|c|c|c|c|}
\hline \multirow[t]{2}{*}{ N. ${ }^{\circ}$} & \multirow[t]{2}{*}{ Ítems } & \multicolumn{2}{|c|}{$\begin{array}{l}\text { Totalmente } \\
\text { en } \\
\text { desacuerdo }\end{array}$} & \multicolumn{2}{|c|}{$\begin{array}{c}\text { En } \\
\text { desacuerdo }\end{array}$} & \multicolumn{2}{|c|}{$\begin{array}{c}\text { Ni de } \\
\text { acuerdo ni } \\
\text { en } \\
\text { desacuerdo }\end{array}$} & \multicolumn{2}{|c|}{$\begin{array}{c}\text { De } \\
\text { acuerdo }\end{array}$} & \multicolumn{2}{|c|}{$\begin{array}{l}\text { Totalmente } \\
\text { de acuerdo }\end{array}$} \\
\hline & & $\mathrm{F}$ & $\%$ & $\mathrm{~F}$ & $\%$ & $\mathrm{~F}$ & $\%$ & $\mathrm{~F}$ & $\%$ & $\mathrm{~F}$ & $\%$ \\
\hline 01 & $\begin{array}{l}\text { ¿Está de acuerdo que la } \\
\text { asignación del presupuesto } \\
\text { participativo asegura la } \\
\text { transparencia del gasto } \\
\text { municipal? }\end{array}$ & 2 & 8,0 & 11 & 44,0 & 3 & 12,0 & 8 & 32,0 & 1 & 4,0 \\
\hline 02 & $\begin{array}{l}\text { ¿Está de acuerdo que la } \\
\text { asignación del presupuesto } \\
\text { participativo asegura la } \\
\text { equidad del gasto } \\
\text { municipal? }\end{array}$ & 1 & 4,0 & 11 & 44,0 & 4 & 16,0 & 7 & 28,0 & 2 & 8,0 \\
\hline 03 & $\begin{array}{l}\text { ¿Está de acuerdo que la } \\
\text { asignación del presupuesto } \\
\text { participativo asegura la } \\
\text { igualdad del gasto } \\
\text { municipal? }\end{array}$ & 1 & 4,0 & 16 & 64,0 & 3 & 12,0 & 3 & 12,0 & 2 & 8,0 \\
\hline 04 & $\begin{array}{l}\text { ¿Está de acuerdo que la } \\
\text { asignación del presupuesto } \\
\text { participativo asegura la } \\
\text { eficiencia del gasto } \\
\text { municipal? }\end{array}$ & 1 & 4,0 & 14 & 56,0 & 4 & 16,0 & 5 & 20,0 & 1 & 4,0 \\
\hline 05 & $\begin{array}{l}\text { ¿Está de acuerdo que la } \\
\text { asignación del presupuesto } \\
\text { participativo asegura la } \\
\text { eficacia del gasto municipal? }\end{array}$ & 1 & 4,0 & 16 & 64,0 & 2 & 8,0 & 5 & 20,0 & 1 & 4,0 \\
\hline 06 & $\begin{array}{l}\text { ¿Está de acuerdo que la } \\
\text { asignación del presupuesto }\end{array}$ & & & & & & & & & & \\
\hline & $\begin{array}{l}\text { participativo asegura la } \\
\text { competitividad del gasto } \\
\text { municipal? }\end{array}$ & 3 & 12,0 & 12 & 48,0 & 6 & 24,0 & 2 & 8.0 & 2 & 8,0 \\
\hline 07 & $\begin{array}{l}\text { ¿Está de acuerdo que el } \\
\text { presupuesto participativo es } \\
\text { una estrategia política de } \\
\text { beneficio al distrito? }\end{array}$ & 1 & 4,0 & 13 & 52,0 & 5 & 20,0 & 5 & 20,0 & 1 & 4,0 \\
\hline
\end{tabular}


Tabla 6

Ejecutar el presupuesto participativo (continuación)

\begin{tabular}{|c|c|c|c|c|c|c|c|c|c|c|c|}
\hline \multirow[t]{2}{*}{ N. ${ }^{\circ}$} & \multirow[t]{2}{*}{ Ítems } & \multicolumn{2}{|c|}{$\begin{array}{c}\text { Totalmente } \\
\text { en } \\
\text { desacuerdo }\end{array}$} & \multicolumn{2}{|c|}{$\begin{array}{c}\text { En } \\
\text { desacuerdo }\end{array}$} & \multicolumn{2}{|c|}{$\begin{array}{c}\text { Ni de } \\
\text { acuerdo ni } \\
\text { en } \\
\text { desacuerdo }\end{array}$} & \multicolumn{2}{|c|}{$\begin{array}{c}\text { De } \\
\text { acuerdo }\end{array}$} & \multicolumn{2}{|c|}{$\begin{array}{l}\text { Totalmente } \\
\text { de acuerdo }\end{array}$} \\
\hline & & $\mathrm{F}$ & $\%$ & $\mathrm{~F}$ & $\%$ & $\mathrm{~F}$ & $\%$ & $\mathrm{~F}$ & $\%$ & $\mathrm{~F}$ & $\%$ \\
\hline 08 & $\begin{array}{l}\text { ¿Está de acuerdo que la } \\
\text { designación del } \\
\text { presupuesto participativo } \\
\text { debe involucrar a todos los } \\
\text { representantes de la } \\
\text { comunidad distrital? }\end{array}$ & 2 & 8,0 & 13 & 52,0 & 4 & 16,0 & 5 & 20,0 & 1 & 4,0 \\
\hline 09 & $\begin{array}{l}\text { ¿Está de acuerdo que el } \\
\text { presupuesto participativo } \\
\text { sea conocido por toda la } \\
\text { comunidad distrital? }\end{array}$ & 0 & 0,0 & 9 & 36,0 & 4 & 16,0 & 10 & 40,0 & 2 & 8,0 \\
\hline 10 & $\begin{array}{l}\text { ¿Está de acuerdo que la } \\
\text { estrategia de distribuir el } \\
\text { presupuesto beneficia a } \\
\text { toda la comunidad? }\end{array}$ & 0 & 0,0 & 16 & 64,0 & 4 & 16,0 & 2 & 8,0 & 3 & 12,0 \\
\hline 11 & $\begin{array}{l}\text { ¿Está de acuerdo que la } \\
\text { estrategia de distribuir el } \\
\text { presupuesto hace justicia } \\
\text { para todos? }\end{array}$ & 2 & 8,0 & 16 & 64,0 & 4 & 16,0 & 2 & 8,0 & 1 & 4,0 \\
\hline 12 & $\begin{array}{l}\text { ¿Está de acuerdo que la } \\
\text { estrategia de distribuir el } \\
\text { presupuesto beneficia a los } \\
\text { más necesitados? }\end{array}$ & 1 & 4,0 & 15 & 60,0 & 4 & 16,0 & 3 & 12,0 & 2 & 8,0 \\
\hline & Total & 1 & 4,0 & 13 & 52,0 & 4 & 16,0 & 5 & 20,0 & 2 & 8,0 \\
\hline
\end{tabular}

Nota: Cuestionario aplicado a los integrantes de la muestra de estudio

En la tabla 6 de la dimensión ejecutar presupuesto participativo, se observa que el52\% representado por 13 delegados de autoridades locales manifestaron estar en desacuerdo con el cumplimiento de estos ítems de dimensión, el 20\% representado por 5 encuestados están de acuerdo, el $16 \%$ están ni de acuerdo ni en desacuerdo representado por 4 delegados, el 8,0\% representado por 2 delegados expresan estar totalmente de acuerdo y $4 \%$ representado por 1 encuestado manifestó estar totalmente en desacuerdo. Asimismo, son 4 los indicadores (ítems 3, 5, 10, 11) con el 64\% y representado con 16 delegados en cada ítem los que tienen mayor incidencia en la decisión de estar en desacuerdo de que la asignación del presupuesto participativo asegura la igualdad y la eficacia del gasto municipal, que la forma de distribuir el presupuesto beneficia a toda la comunidad distrital, y la forma de hacer justicia para todos; le si el indicador 12 con el $60 \%$ representado por 15 encuestados enfatizan que la distribución presupuestal beneficia a los más necesitados, el indicador 4 con el 56\% representado 14 delegados también están 
desacuerdo que la asignación del presupuesto participativo asegura la eficiencia del gasto municipal, los indicadores 7 y 8 con el $52 \%$ representado por 13 personas en cada uno de ellos indicaron estar totalmente en desacuerdo de que el presupuesto participativo es una estrategia política de beneficio al distrito y en otro ítem en que la designación del presupuesto participativo se debe involucrar a todos los representantes de la comunidad distrital; el indicador 6 con el $48 \%$ representado por 12 personas indicaron estar totalmente en desacuerdo de que la asignación del presupuesto participativo asegure la competitividad del gasto municipal y, los ítems 1 y 2 con el $44 \%$ representado por 11 encuestados expresan que el presupuesto participativo asegura la transparencia y la equidad del gasto municipal; finalmente el ítem 9 con el $36 \%$ representado por 9 delegados dicen estar en desacuerdo de que el presupuesto participativo sea conocido por toda la comunidad distrital.

En el nivel de acuerdo, el ítem 9 con el $40 \%$ representado por 10 delegados representan el mayor número de incidencia, le sigue el ítem 1 con el $32 \%$ representado por 8 delegados, continua el indicador 2 con el $28 \%$ representado por 7 encuestados, siguen los indicadores 4, 5, 7 y 8 con el $20 \%$ representados por 5 personas por cada indicador; los indicadores 3 y 12 con el $12 \%$ representados por 3 encuestados, y finalmente los indicadores 6,10 y 11 con el $8 \%$ representado por 2 delegados.

En el nivel ni de acuerdo ni en desacuerdo el indicador 6 con el 24\% representado por 6 delegados son los que tienen mayor incidencia, le sigue el indicador 7 con el $20 \%$ representado por 5 personas, continúan los indicadores $2,4,8,9,10,11$ y 12 cada uno de ellos tiene el $16 \%$ representado por 4 personas por cada indicador, los indicadores 1 y 3 con el $12 \%$ representado por 3 delegados; y finalmente el indicador 5 con el $8 \%$ representado por 2 personas. En el nivel totalmente de acuerdo el de mayor puntaje es el ítem 10 con el $12 \%$, le sigue los indicadores $2,3,6,9$ y 12 con el $8 \%$ representado por 2 sujetos cada uno; y finalmente los ítems $1,4,5,7,8$ y 11 con el 4\% representado por 1 delegado.

En el nivel totalmente en desacuerdo, el ítem 6 con el 12\% representado por 3 delegados es el de mayor porcentaje, le sigue los ítems 1,8 y 11 con el $8 \%$ representado por 2 personas, y finamente los ítems 2, 3, 4, 5, 7 y 12 con el 4\% representado por 1 delegado. 
Tabla 7

Beneficios de distribución presupuestal

\begin{tabular}{|c|c|c|c|c|c|c|c|c|c|c|c|}
\hline \multirow[t]{2}{*}{ N. ${ }^{o}$} & \multirow[t]{2}{*}{ Ítems } & \multicolumn{2}{|c|}{$\begin{array}{l}\text { Totalmente } \\
\text { en } \\
\text { desacuerdo }\end{array}$} & \multicolumn{2}{|c|}{$\begin{array}{c}\text { En } \\
\text { desacuerdo }\end{array}$} & \multicolumn{2}{|c|}{$\begin{array}{c}\text { Ni de } \\
\text { acuerdo ni } \\
\text { en } \\
\text { desacuerdo }\end{array}$} & \multicolumn{2}{|c|}{$\begin{array}{c}\text { De } \\
\text { acuerdo }\end{array}$} & \multicolumn{2}{|c|}{$\begin{array}{l}\text { Totalmente } \\
\text { de acuerdo }\end{array}$} \\
\hline & & $\mathrm{F}$ & $\%$ & $\mathrm{~F}$ & $\%$ & $\mathrm{~F}$ & $\%$ & $\mathrm{~F}$ & $\%$ & $\mathrm{~F}$ & $\%$ \\
\hline 01 & $\begin{array}{l}\text { ¿Considera Ud. que los } \\
\text { organizadores del } \\
\text { presupuesto participativo } \\
\text { aseguran una conducción } \\
\text { apropiada? }\end{array}$ & 0 & 0,0 & 14 & 56,0 & 5 & 20,0 & 5 & 20,0 & 1 & 4,0 \\
\hline 02 & $\begin{array}{l}\text { ¿Considera Ud. que la } \\
\text { preparación de los } \\
\text { responsables municipales } \\
\text { asegura la viabilidad } \\
\text { presupuestal? }\end{array}$ & 1 & 4,0 & 12 & 48,0 & 6 & 24,0 & 5 & 20,0 & 1 & 4,0 \\
\hline 03 & $\begin{array}{l}\text { ¿Considera Ud. que la } \\
\text { preparación de los } \\
\text { responsables municipales } \\
\text { asegura el control del } \\
\text { manejo presupuestal? }\end{array}$ & 1 & 4,0 & 10 & 40,0 & 5 & 20,0 & 7 & 28,0 & 2 & 8,0 \\
\hline 04 & $\begin{array}{l}\text { ¿Considera Ud. que los } \\
\text { ciudadanos participan } \\
\text { activamente en los asuntos } \\
\text { presupuestales municipales? }\end{array}$ & 3 & 12,0 & 13 & 52,0 & 4 & 16,0 & 4 & 16,0 & 1 & 4,0 \\
\hline 05 & $\begin{array}{l}\text { ¿Considera Ud. que los } \\
\text { ciudadanos aseguran la } \\
\text { transparencia del } \\
\text { presupuesto municipal? }\end{array}$ & 5 & 20,0 & 13 & 52,0 & 2 & 8,0 & 4 & 16,0 & 1 & 4,0 \\
\hline 06 & $\begin{array}{l}\text { ¿Considera Ud. que la } \\
\text { participación de los } \\
\text { ciudadanos asegura una } \\
\text { distribución justa del } \\
\text { presupuesto municipal? }\end{array}$ & 2 & 8,0 & 12 & 48,0 & 2 & 8,0 & 7 & 28,0 & 2 & 8,0 \\
\hline 07 & $\begin{array}{l}\text { ¿Considera Ud. que el } \\
\text { presupuesto participativo } \\
\text { asegura un gasto honesto? }\end{array}$ & 3 & 12,0 & 12 & 48,0 & 5 & 20,0 & 4 & 16,0 & 1 & 4,0 \\
\hline 08 & $\begin{array}{l}\text { ¿Considera Ud. que el } \\
\text { presupuesto participativo } \\
\text { mejora las condiciones } \\
\text { sociales de la población? }\end{array}$ & 1 & 4,0 & 9 & 36,0 & 4 & 16,0 & 9 & 36,0 & 2 & 8,0 \\
\hline
\end{tabular}


Tabla 7

Beneficios de distribución presupuestal (continuación)

\begin{tabular}{|c|c|c|c|c|c|c|c|c|c|c|c|}
\hline & \multirow[t]{2}{*}{ Ítems } & \multicolumn{2}{|c|}{$\begin{array}{l}\text { Totalmente } \\
\text { en } \\
\text { desacuerdo }\end{array}$} & \multicolumn{2}{|c|}{$\begin{array}{l}\text { En } \\
\text { desacuerdo }\end{array}$} & \multicolumn{2}{|c|}{$\begin{array}{l}\text { Ni de } \\
\text { acuerdo ni } \\
\text { en } \\
\text { desacuerdo }\end{array}$} & \multicolumn{2}{|c|}{$\begin{array}{l}\text { De } \\
\text { acuerdo }\end{array}$} & \multicolumn{2}{|c|}{$\begin{array}{l}\text { Totalmente } \\
\text { de acuerdo }\end{array}$} \\
\hline & & $\mathrm{F}$ & $\%$ & $\mathrm{~F}$ & $\%$ & $\mathrm{~F}$ & $\%$ & $\mathrm{~F}$ & $\%$ & $\mathrm{~F}$ & $\%$ \\
\hline 09 & $\begin{array}{l}\text { ¿Considera Ud. que el } \\
\text { presupuesto participativo } \\
\text { mejora las condiciones de } \\
\text { los más necesitados? }\end{array}$ & 3 & 12,0 & 7 & 28,0 & 5 & 20,0 & 7 & 28,0 & 3 & 12,0 \\
\hline & Total & 2 & 8,0 & 11 & 44,0 & 4 & 16,0 & 6 & 24,0 & 2 & 8,0 \\
\hline
\end{tabular}

Nota: Cuestionario aplicado a los integrantes de la muestra de estudio

En la tabla 7, de la dimensión beneficios de distribución presupuestal, se observa que e144\% representado por 11 delegados de autoridades locales manifestaron estar en desacuerdo con el cumplimiento de estos ítems de dimensión, el 24\% representado por 6 encuestados están de acuerdo, el 16\% representado por 4 personas están ni de acuerdo ni en desacuerdo y el 8,0\% representado por 2 delegados expresan estar totalmente de acuerdo y totalmente en desacuerdo respectivamente.

Así mismo, el indicador con mayor incidencia en la decisión de estar en desacuerdo fue el indicador 1 con el 56\% representado por 14 delegados referente a que los organizadores del presupuesto participativo aseguran a la población una conducción asegurada, le sigue los indicadores 4 y 5 con el $52 \%$ representado por 13 delegados en donde los ciudadanos participan activamente en los asuntos presupuestales y que también aseguran transparencia de la distribución del presupuesto municipal, continúa con los indicadores 2, 6 y 7 con el $48 \%$ representado por 12 delegados manifestaron que la preparación de los responsables municipales asegura la viabilidad presupuestal, aseguran un distribución justa y también un gasto honesto; le sigue el ítem 3 con el $40 \%$ representado por 10 delegados de que la preparación de los responsables municipales asegura el control del manejo presupuestal, continúa con el indicador 8 con el $36 \%$ representado por 9 delegados resaltan que el presupuesto participativo mejora las condiciones sociales de la población, y finalmente el indicador 9 con el $28 \%$ representado por 7 personas de que el presupuesto mejora las condiciones de los más necesitados. En el nivel ni de acuerdo ni en desacuerdo, el de mayor incidencia es ítem 2 con el $24 \%$ representado por 6 delegados, le sigue los ítems 1, 3, 6, 7 y 9 con el 20\% representado con 5 delegado cada uno, continúa con los ítems 4 y 8 con el $16 \%$ representado por 4 delegados y el ítem 5 con el $8 \%$ representado por 2 delgados.

En el nivel de acuerdo el indicador con mayor incidencia es el ítem 8 con el 36\% representado por 9 delegados, le sigue los indicadores 3 y 9 con el $28 \%$ representado por 
7 delegados, continúa los ítems 1 y 2 con el $20 \%$ representado por 5 encuestados y loa ítems $4,5,6$ y 7 con el $16 \%$ representado por 4 delegados.

En el nivel totalmente en desacuerdo, el indicador de mayor incidencia fue el indicador 5 con el $20 \%$ representado por 5 delegados, le sigue los indicadores 7 y 9 con el $12 \%$ representado por 3 delgados, continúa el indicador 6 con $8 \%$ representado por 2 personas, finalmente le sigue los indicadores 2,3 y 8 con el $4 \%$ representado por 1 delegado respectivamente. En el nivel totalmente de acuerdo, el indicador de mayor incidencia es el ítem 9 con el 12\% representado por 3 delgados, le sigue los ítems 3 y 8 con el $8 \%$ representado por 2 delegados; y finalmente están los ítems 1, 2, 4, 5, 6 y 7 con el $4 \%$ y representado por y persona respectivamente.

\section{Tabla 8}

Mecanismos de planificación y concertación

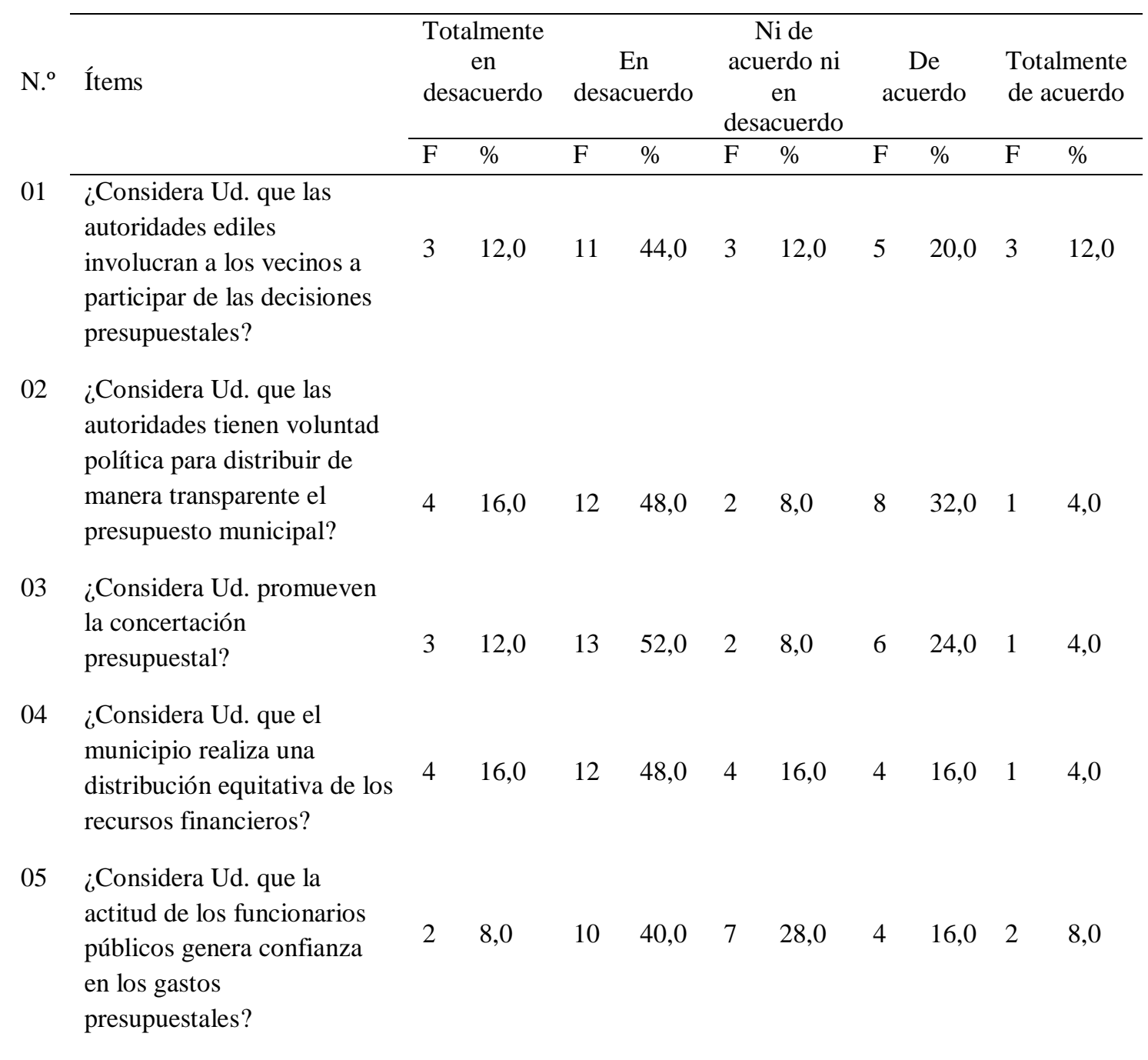




\section{Tabla 8}

Mecanismos de planificación y concertación

\begin{tabular}{|c|c|c|c|c|c|c|c|c|c|c|c|}
\hline \multirow[t]{2}{*}{ N. ${ }^{\circ}$} & \multirow[t]{2}{*}{ Ítems } & \multicolumn{2}{|c|}{$\begin{array}{l}\text { Totalmente } \\
\text { en } \\
\text { desacuerdo }\end{array}$} & \multicolumn{2}{|c|}{$\begin{array}{c}\text { En } \\
\text { desacuerdo }\end{array}$} & \multicolumn{2}{|c|}{$\begin{array}{c}\text { Ni de } \\
\text { acuerdo ni } \\
\text { en } \\
\text { desacuerdo }\end{array}$} & \multicolumn{2}{|c|}{$\begin{array}{c}\text { De } \\
\text { acuerdo }\end{array}$} & \multicolumn{2}{|c|}{$\begin{array}{l}\text { Totalmente } \\
\text { de acuerdo }\end{array}$} \\
\hline & & $\mathrm{F}$ & $\%$ & $\mathrm{~F}$ & $\%$ & $\mathrm{~F}$ & $\%$ & $\mathrm{~F}$ & $\%$ & $\mathrm{~F}$ & $\%$ \\
\hline 06 & $\begin{array}{l}\text { ¿Considera Ud. que la } \\
\text { distribución equitativa del } \\
\text { presupuesto ayuda mucho a } \\
\text { reducir desigualdades } \\
\text { sociales? }\end{array}$ & 2 & 8,0 & 15 & 60,0 & 1 & 4,0 & 4 & 16,0 & 3 & 12,0 \\
\hline 07 & $\begin{array}{l}\text { ¿Considera Ud. que los } \\
\text { acuerdos presupuestales se } \\
\text { respetan a cabalidad? }\end{array}$ & 2 & 8,0 & 14 & 56,0 & 5 & 20,0 & 1 & 4,0 & 3 & 12,0 \\
\hline 08 & $\begin{array}{l}\text { ¿Considera Ud. que los } \\
\text { gastos presupuestales son } \\
\text { monitoreados por la } \\
\text { ciudadanía? }\end{array}$ & 6 & 24,0 & 11 & 44,0 & 4 & 16,0 & 1 & 4,0 & 3 & 12,0 \\
\hline 09 & $\begin{array}{l}\text { ¿Considera Ud. que se } \\
\text { respeta el cronograma de } \\
\text { ejecución de las obras } \\
\text { presupuestales municipales? }\end{array}$ & 5 & 20,0 & 13 & 52,0 & 3 & 12,0 & 3 & 12,0 & 1 & 4,0 \\
\hline & Total & 3 & 12,0 & 12 & 48,0 & 4 & 16,0 & 4 & 16,0 & 2 & 8,0 \\
\hline
\end{tabular}

Nota: Cuestionario aplicado a los integrantes de la muestra de estudio

En la tabla 8, de la dimensión mecanismos de planificación y concertación, se observa que el48\% representado por 12 delegados de autoridades locales manifestaron estar en desacuerdo con el cumplimiento de estos ítems de dimensión, el 16\% representado por 4 encuestados están de acuerdo, y el otro sector ni de acuerdo ni en desacuerdo, el $12 \%$ representado por 3 personas están totalmente en desacuerdo y el 8,0\% representado por 2 delegados expresan estar totalmente de acuerdo.

Así mismo, el indicador con mayor incidencia en la decisión de estar en desacuerdo fue el indicador 6 con el $60 \%$ representado por 15 delegados referente a que la distribución equitativa del presupuesto ayuda mucho a reducir las desigualdades sociales, le sigue el ítem 7 con el 56\% representado por 14 delegados quienes indican que los acuerdos presupuestales se respetan a cabalidad, continúan los ítems 3 y 9 con el 52\% representado por 13 delgados quienes señalan que las autoridades promuevan la concertación presupuestal, y además se respeta el cronograma de ejecución de las obras presupuestales municipales, continúan los ítems 2 y 4 con el $48 \%$ representado por 12 delegados, indican de que las autoridades tienen voluntad política para distribuir de manera transparente el 
presupuesto municipal, y que el municipio realiza una distribución equitativa de los recursos financieros, le sigue los ítems 1 y 8 con el $44 \%$ representado por 11 delegados señalan que las autoridades ediles involucran a los vecinos a participar de las decisiones presupuestales, y que los gastos presupuestales son monitoreados por la ciudadanía, finalmente el indicador 5 con el $40 \%$ representado por 10 delegados señalan que la actitud de los funcionarios públicos genera confianza en los gastos presupuestales.

En el nivel de acuerdo, el indicador de mayor incidencia fue el 2 con el $32 \%$ representado por 8 delegados, le sigue el ítem 3 con el $24 \%$ representado por 6 delegados, continúa el ítem 1 con el $20 \%$ representado por 5 encuestados, le siguen los ítems 4, 5 y 6 con el 16\% representado por 4 encuestados, continúa el ítem 9 con $12 \%$ representado por 3 encuestados, y finalmente, los ítems 7 y 8 con el $4 \%$ representado por 1 delegado respectivamente. En el nivel ni de acuerdo ni en desacuerdo, el indicador de mayor incidencia fue el 5 con el $28 \%$ representado por 7 delegados, le sigue el indicador 7 con el $20 \%$ representado por 5 personas, continúan los ítems 4 y 8 con 16\% representado por 4 delegados, le sigue los ítems 1 y 9 con el $12 \%$ representado por 3 encuestados, continúan los ítems 2 y 3 con el $8 \%$ representado por 2 delegados; y finalmente, el ítem 6 con $4 \%$ representado por 1 encuestado. En el nivel totalmente en desacuerdo, el indicador de mayor incidencia fue el ítem 8 con el $24 \%$ representado por 6 delegados, le sigue el ítem 9 con el $20 \%$ representado por 5 encuestados, continúan los ítems 2 y 4 con $16 \%$ representado por 4 delegados, le sigue los ítems 1 y 3 con el $12 \%$ representado por 3 encuestados, finalmente los ítems 5, 6 y 7 con el $8 \%$ representado por 2 delegados.

En el nivel totalmente de acuerdo, los ítems de mayor incidencia fueron 1, 6, 7 y 8 con el $12 \%$ representado por 3 delgados, le sigue el ítem 5 con $8 \%$ representado por 2 delegados, y finalmente, los ítems 2, 3, 4 y 9 representado por 1 delgado respectivamente.

\section{Tabla 9}

Resultados de ejecución de presupuesto

\begin{tabular}{|c|c|c|c|c|c|c|c|c|c|c|c|}
\hline \multirow[t]{2}{*}{ N. ${ }^{\circ}$} & \multirow[t]{2}{*}{ Ítems } & \multicolumn{2}{|c|}{$\begin{array}{c}\text { Totalmente } \\
\text { en } \\
\text { desacuerdo }\end{array}$} & \multicolumn{2}{|c|}{$\begin{array}{c}\text { En } \\
\text { desacuerdo }\end{array}$} & \multicolumn{2}{|c|}{$\begin{array}{c}\text { Ni de } \\
\text { acuerdo ni } \\
\text { en } \\
\text { desacuerdo }\end{array}$} & \multicolumn{2}{|c|}{$\begin{array}{c}\text { De } \\
\text { acuerdo }\end{array}$} & \multicolumn{2}{|c|}{$\begin{array}{l}\text { Totalment } \\
\text { de acuerdo }\end{array}$} \\
\hline & & $\mathrm{F}$ & $\%$ & $\mathrm{~F}$ & $\%$ & $\mathrm{~F}$ & $\%$ & $\mathrm{~F}$ & $\%$ & $\mathrm{~F}$ & $\%$ \\
\hline 01 & $\begin{array}{l}\text { ¿Considera Ud. que con el } \\
\text { presupuesto participativo se } \\
\text { asegura la calidad de la } \\
\text { obra? }\end{array}$ & 4 & 16,0 & 12 & 48,0 & 3 & 12,0 & 5 & 20,0 & 1 & 4,0 \\
\hline 02 & $\begin{array}{l}\text { ¿Considera Ud. que con el } \\
\text { presupuesto consensuado } \\
\text { asegura la confianza en la } \\
\text { población? }\end{array}$ & 2 & 8,0 & 11 & 44,0 & 3 & 12,0 & 7 & 28,0 & 2 & 8,0 \\
\hline
\end{tabular}


Tabla 9

Resultados de ejecución de presupuesto (continuación)

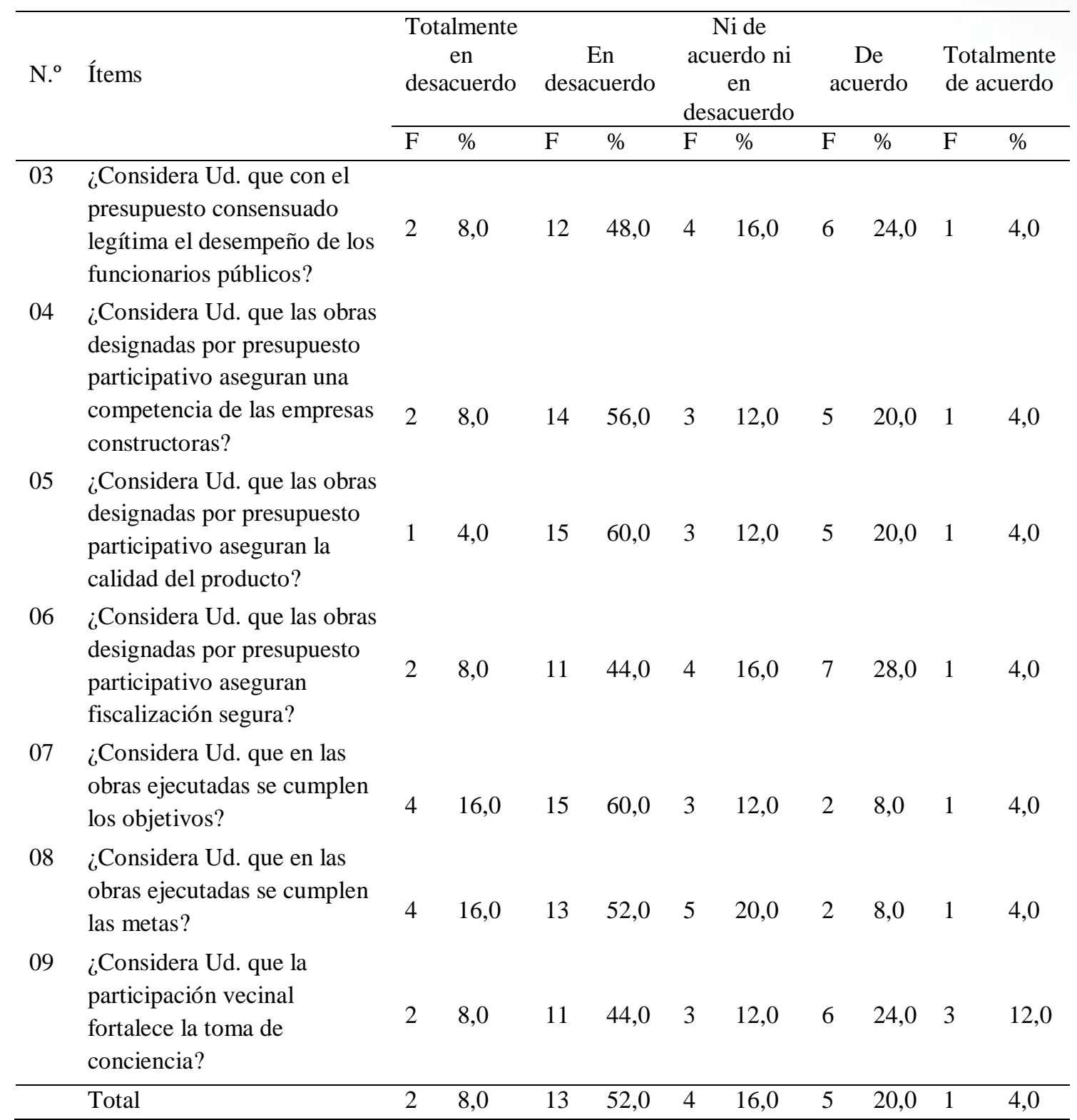

Nota: Cuestionario aplicado a los integrantes de la muestra de estudio

En la tabla 9, de la dimensión resultados de ejecución del presupuesto el52\% representado por 13 delegados de autoridades locales manifestaron estar en desacuerdo con el cumplimiento de estos ítems de dimensión, el 20\% representado por 5 encuestados están de acuerdo, el $16 \%$ representado por 4 personas están ni de acuerdo ni en desacuerdo y el $4,0 \%$ representado por 1 delegado expresa estar totalmente de acuerdo.

Así mismo, el indicador con mayor incidencia en la decisión de estar en desacuerdo fueron los indicadores 5 y 7 con el $60 \%$ representado por 15 delegados cada uno referente 
a que las obras designadas por presupuesto participativo aseguran la calidad del producto y también que las obras ejecutadas cumplen con los objetivos propuestos, le sigue el ítem 4 con el $56 \%$ representado por 14 delegados quienes indican que las obras designadas por presupuesto participativo aseguran la competencia de las empresas constructoras, continúa el ítem 8 con el 52\% representado por 13 delegados indicaron que las obras ejecutadas cumplen con las metas establecidas, le sigue los ítems 1 y 3 con el 48\% representado por 12 delgados quienes señalan que el presupuesto participativo asegure la calidad de la obra, y que con el presupuesto consensuado legitima el desempeño de los funcionarios públicos, continúan los ítems 2, 6 y 9 con el $44 \%$ representado por 11delegados, indican que con el presupuesto consensuado asegura la confianza en la población, también que las obras designadas por presupuesto participativo aseguran una fiscalización segura, y que la participación vecinal fortalece la toma de conciencia.

En el nivel de acuerdo, los indicadores de mayor incidencia fueron el 2 y 6 con el $28 \%$ representado por 7 delegados, le sigue los ítems 2 y 9 con el $24 \%$ representado por 6 delegados, continúan los ítems 1,4 y 5 con el $20 \%$ representado por 5 encuestados, le siguen los ítems 7 y 8 con el $8 \%$ representado por 2 encuestados respectivamente. En el nivel ni de acuerdo ni en desacuerdo, el indicador de mayor incidencia fue el 8 con el $20 \%$ representado por 5 delegados, le sigue los indicadores 3 y 6 con el $16 \%$ representado por 4 personas, continúan los ítems 1, 2, 4, 5, 7 y 9 con 12\% representado por 3 delegados. En el nivel totalmente en desacuerdo, el indicador de mayor incidencia fueron los ítems 7 y 8 con el $16 \%$ representado por 4 delegados, le sigue los ítems 2. 3, 4, 6 y 9 con $8 \%$ representado por 2 delegados, le sigue el ítem 5 con el $4 \%$ representado por 1 delegado.

\section{Objetivo específico 2}

Describir los factores que influyen en participación ciudadana para ejecutar el presupuesto municipal.

\section{Tabla 10}

Factores influyentes de participación ciudadana

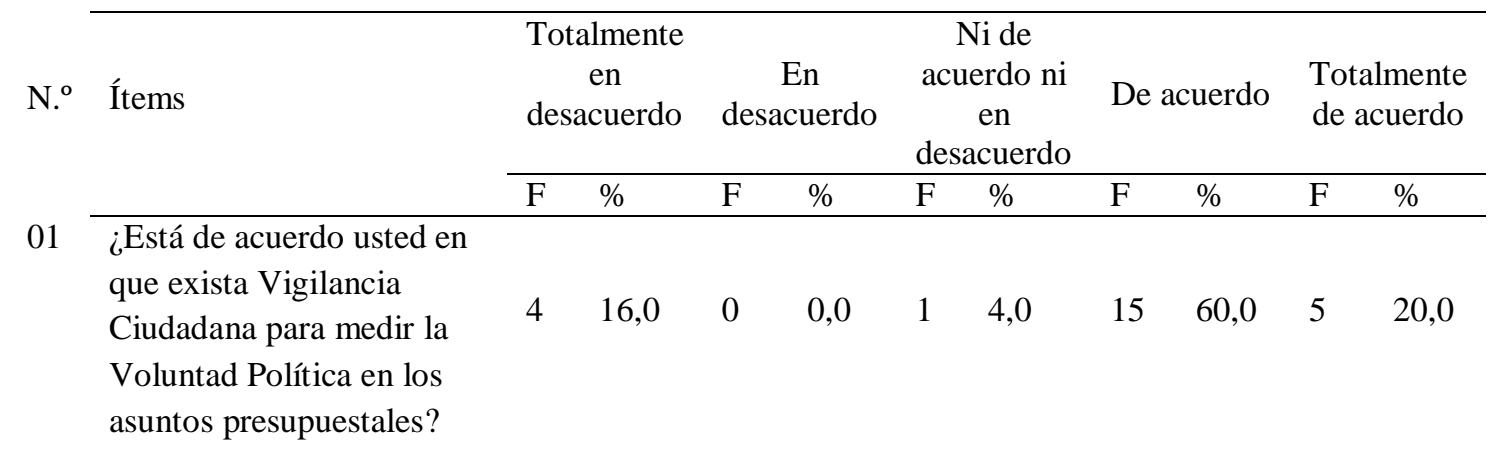




\section{Tabla 10}

Factores influyentes de participación ciudadana (continuación)

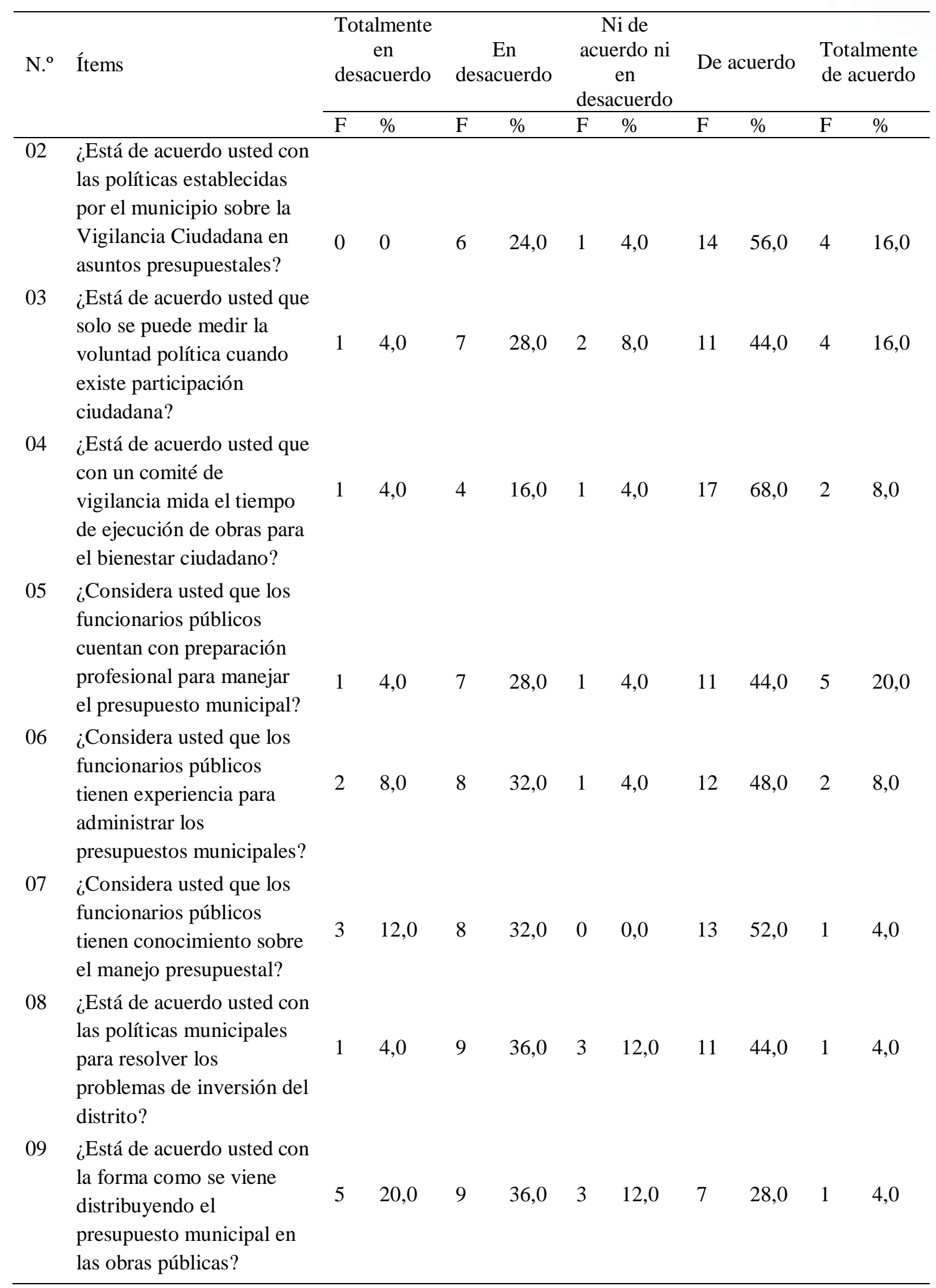




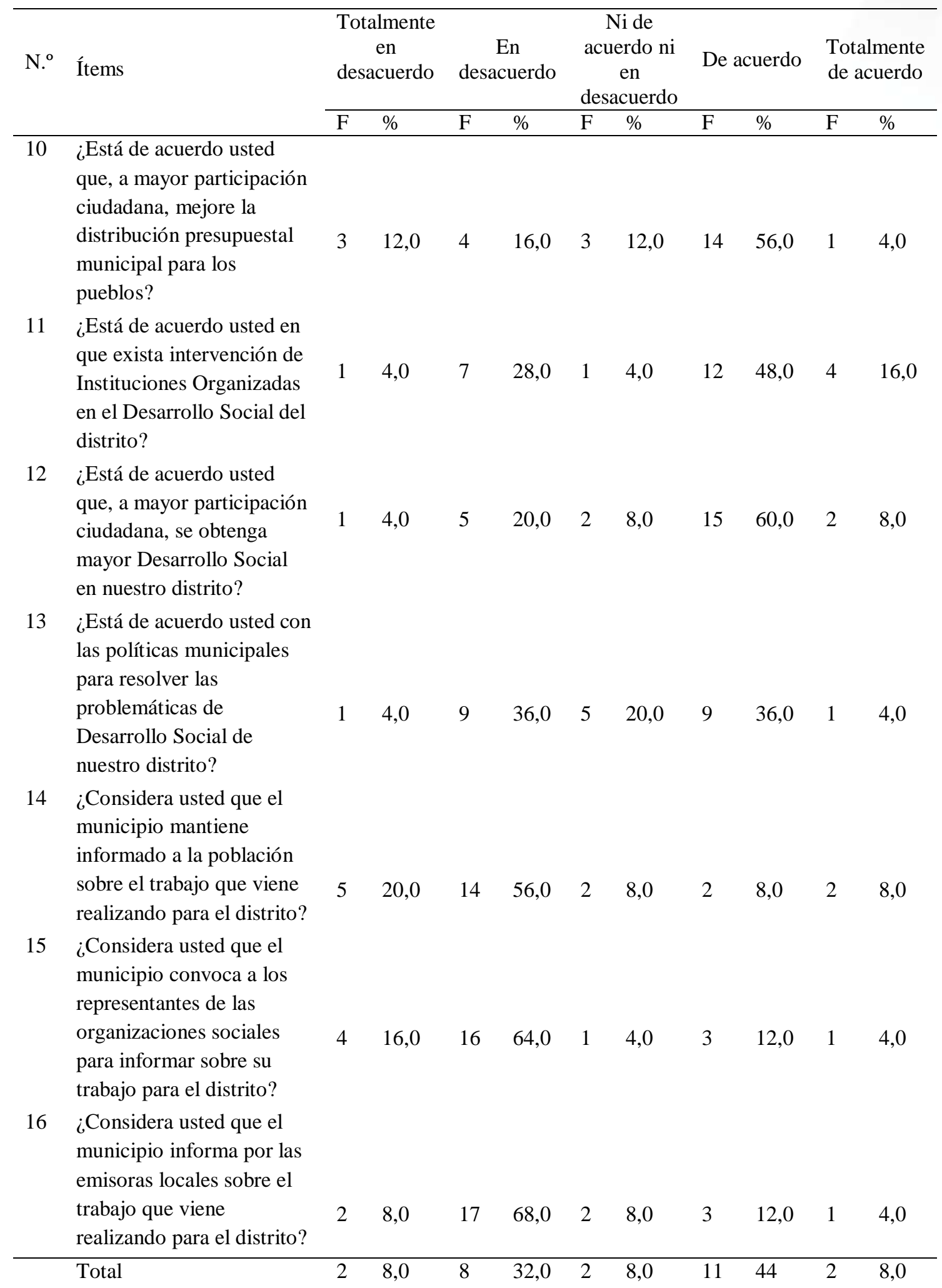

Nota: Cuestionario aplicado a los integrantes de la muestra de estudio 
En la tabla 10, de la dimensión factores influyentes en la participación ciudadana en el presupuesto participativo el $44 \%$ representado por 11 delegados de autoridades locales manifestaron estar de acuerdo con el cumplimiento de estos ítems de dimensión, el 32\% representado por 8 encuestados están en desacuerdo y el 8,0\% representado por 2 delegados expresaron estar totalmente de acuerdo, totalmente en desacuerdo y ni de acuerdo ni en desacuerdo respectivamente.

Así mismo, el indicador con mayor incidencia en la decisión de estar de acuerdo fue el indicador 4 con el $68 \%$ representado por 17 delegados referente a comité de vigilancia mida el tiempo de ejecución de obras para el bienestar ciudadano, le sigue los ítems 4 y 12 con el $60 \%$ representado por 15 delegados quienes indica la necesidad de la vigilia ciudadana para medir la Voluntad Política en los asuntos presupuestales, y son conscientes de que a mayor participación ciudadana, se obtenga mayor Desarrollo Social en el distrito. Continúan los ítems 2 y 10 con el 56\% representado por 14 delegados indicaron que es bueno que se establezcan las políticas municipales sobre la Vigilancia Ciudadana en asuntos presupuestales, y que, a mayor participación ciudadana, mejora la distribución presupuestal municipal para los pueblos, le sigue el ítem 7 con el 52\% representado por 13 delegados indicaron que los funcionarios públicos tienen conocimiento sobre el manejo presupuestal, continúa con los ítems 6 y 11 con el 48\% representado por 12 delgados quienes señalan que los funcionarios públicos tienen experiencia para administrar los presupuestos municipales, y están de acuerdo que exista intervención de Instituciones Organizadas en el Desarrollo Social del distrito, le sigue los ítems 3, 5 y 8 con el $44 \%$ representado por 11 delegados, indican que solo se puede medir la voluntad política cuando existe participación ciudadana, que los funcionarios públicos cuentan con preparación profesional para manejar el presupuesto municipal, que existen políticas municipales para resolver los problemas de inversión del distrito, continúa el ítem 9 con el 36\% representado por 9 delegados están de acuerdo de la forma como se viene distribuyendo el presupuesto municipal en las obras públicas.

En el nivel estar en desacuerdo el ítem 16 es el que tiene mayor incidencia con el 68\% representado por 17 delegados, quienes indican que el municipio informa por las emisoras locales sobre el trabajo que viene realizando para el distrito, le sigue el ítem 15 con el $64 \%$ representado por 16 encuestados, quienes indican que el municipio convoca a los representantes de las organizaciones sociales para informar sobre su trabajo para el distrito, continúa el ítem 14 con el 56\% representado por 14 delegados señalan que el municipio mantiene informado a la población sobre el trabajo que viene realizando para el distrito.

En el nivel anterior también se observa que los ítems 8, 9 y 13 muestran el 36\% representados por 9 delegados respectivamente, le sigue los ítems 6 y 7 con el $32 \%$ representado por 8 encuestados, continúa con los ítems 3,5 y 11 con el $28 \%$ representado 
por 7 delegados, le sigue el ítem 2 con el 24\% representado por 6 encuestados, continúa el ítem 12 con el $20 \%$ representado por 5 personas, y finalmente los ítems 4 y 10 con el $16 \%$ representado por 4 delegados respectivamente.

El resto de los otros niveles como estar en total desacuerdo, ni estar de acuerdo ni en desacuerdo y totalmente de acuerdo las cifras porcentuales en su mayoría son mínimas.

\section{Objetivo específico 3}

Formular el plan de fortalecimiento y promoción del presupuesto municipal.

\section{Figura 2}

Plan de fortalecimiento y promoción ciudadana

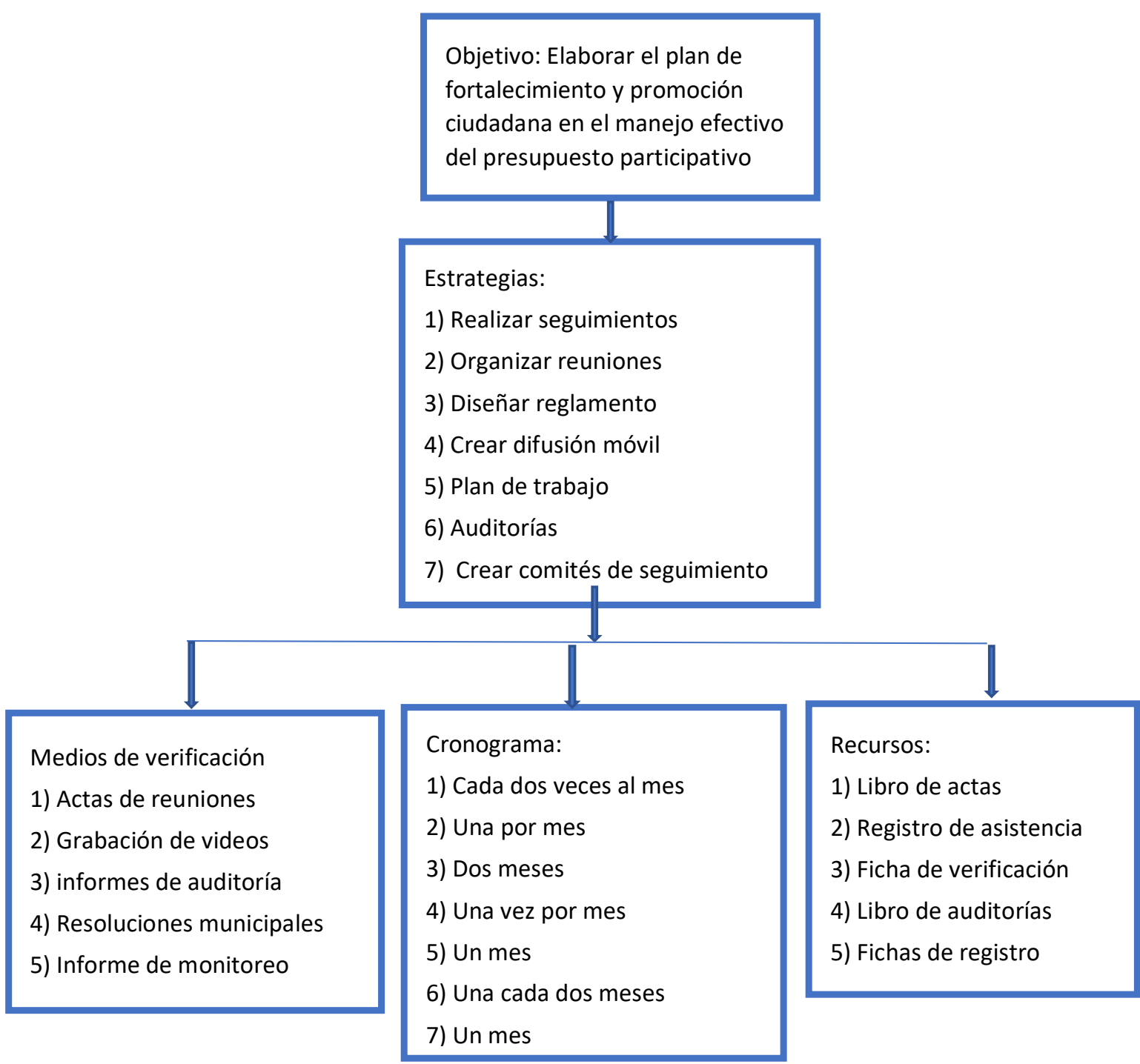


Objetivo específico 4

Validar el plan de fortalecimiento y promoción del presupuesto municipal enfatizando en la validez de contenido.

La validación se realizó con la validación de contenido, es decir por juicio de expertos.

\section{Prueba de normalidad}

Se aplicó para determinar con que prueba se debe comprobar las hipótesis.

Kolmogorov-Smirnov: se aplica en muestras mayores a 50 sujetos y ShapiroWilk: se aplica en muestras de 50 sujetos a menos.

\section{Criterios de normalidad:}

Sig. $=>\alpha$ aceptar $\mathrm{H} 0=$ los datos provienen de una distribución normal. Sig. $<\alpha$ aceptar $\mathrm{Hi}=$ los datos no provienen de una distribución normal.

\section{Tabla 11}

Prueba de normalidad de las variables participación ciudadana y presupuesto participativo

\begin{tabular}{lllll}
\hline & & & Shapiro-Wilk & \\
& & Estadístico & gl & Sig. \\
\hline V.I & Participación ciudadana &, 943 & 25 &, 171 \\
V.D & Presupuesto participativo &, 851 & 25 &, 002 \\
\hline
\end{tabular}

Interpretación: Por haber trabajado con muestras menores a 50 sujetos, se trabajó con la prueba de normalidad Shapiro-WilkKolmogorov-Smirnov (tabla 11). Asimismo, en el análisis de normalidad se percibe que la variable Participación ciudadana obtuvo Sig. = $1.171>0,05$ y la variable presupuesto participativo Sig. $=0.002<0,05$ valores mostraron que los datos no provienen de una distribución normal, por lo que correspondió usar la prueba no paramétrica de correlación de Pearson.

\section{Resultados inferenciales}

\section{Hipótesis general}

$\mathrm{H}_{\mathrm{i}}$ : Existe una relación significativa entre la participación ciudadana y el presupuesto participativo en la gestión edil de Canchaque-Huancabamba.

$\mathrm{H}_{\mathrm{o}}$ : No existe una relación significativa entre la participación ciudadana y el presupuesto participativo en la gestión edil de Canchaque-Huancabamba. 
Tabla 12

Correlación entre participación ciudadana y presupuesto participativo

\begin{tabular}{llc}
\hline & & VD: Presupuesto participativo \\
\hline VI: Participación ciudadana & Correlación de Pearson &, 272 \\
& Sig. (bilateral) &, 049 \\
& $\mathrm{~N}$ & 25 \\
\hline
\end{tabular}

Fuente: Cuestionarios de participación ciudadana y presupuesto participativo

La tabla 12 muestra una correlación positiva baja y un nivel de significancia menor a, 005, lo que permite validar la hipótesis de investigación, es decir, existe una relación significativa entre la participación ciudadana y el presupuesto participativo.

En el siguiente estudio Plan de fortalecimiento y promoción para la participación ciudadana en el proceso del presupuesto participativo en la gestión municipal de Canchaque-Huancabamba se conocieron diversos hallazgos, vinculados con los objetivos establecidos en esta investigación, en donde se da cuenta una vinculación o no con los antecedentes anteriores a la finalización de este estudio, así como la lista de teorías vinculadas a cada una de las variables, las cuales justifican lo que se describe en este producto académico.

Así, en la investigación se diagnosticó (primer objetivo específico) que, la participación ciudadana y el presupuesto participativo en la comuna edil de un distrito rural, referente a las fases de participación ciudadana, los delegados de autoridades locales expresaron que el $40 \%$ representado por 10 delegados manifestaron estar en desacuerdo con el cumplimiento de estos ítems de dimensión, el 24\% representado por 6 encuestados están de acuerdo, el 20\% está en desacuerdo; el 8,0\% expresan estar ni de acuerdo ni en desacuerdo y también están totalmente de acuerdo, ambos de manera respectiva (tabla 4); respecto a los mecanismos de participación ciudadana, en la versión de los delegados, el $28 \%$ representado por 7 delegados manifestaron estar en desacuerdo y en la misma proporción de acuerdo con el cumplimiento de estos ítems de dimensión, el 24\% representado por 6 encuestados están de acuerdo, el 20\% están totalmente en desacuerdo, el $12 \%$ representado por 3 delegados expresaron estar ni de acuerdo ni en desacuerdo, y el 8,0\% señalaron estar totalmente de acuerdo (tabla 5); en cuanto a la ejecución del presupuesto, el 52\% representado por 13 delegados de autoridades locales manifestaron estar en desacuerdo con el cumplimiento de estos ítems de dimensión, el $20 \%$ representado por 5 encuestados están de acuerdo, el 16\% están ni de acuerdo ni en desacuerdo representado por 4 delegados, el 8,0\% representado por 2 delegados expresan estar totalmente de acuerdo y $4 \%$ representado por 1 encuestado manifestó estar totalmente en desacuerdo (tabla 6); en referencia a los beneficios de distribución del presupuesto participativo, el $44 \%$ representado por 11 delegados de autoridades locales manifestaron estar en desacuerdo con el cumplimiento de estos ítems de dimensión, el $24 \%$ representado por 6 encuestados están de acuerdo, el 16\% representado por 4 
personas están ni de acuerdo ni en desacuerdo y el 8,0\% representado por 2 delegados expresan estar totalmente de acuerdo y totalmente en desacuerdo respectivamente (tabla 7); respecto a los mecanismos de planificación y concertación del presupuesto participativo, el $48 \%$ representado por 12 delegados de autoridades locales manifestaron estar en desacuerdo con el cumplimiento de estos ítems de dimensión, el 16\% representado por 4 encuestados están de acuerdo, y el otro sector ni de acuerdo ni en desacuerdo, el 12\% representado por 3 personas están totalmente en desacuerdo y el 8,0\% representado por 2 delegados expresan estar totalmente de acuerdo (tabla 8); en cuanto a la ejecución del presupuesto participativo, el 52\% representado por 13 delegados de autoridades locales manifestaron estar en desacuerdo con el cumplimiento de estos ítems de dimensión, el 20\% representado por 5 encuestados están de acuerdo, el $16 \%$ representado por 4 personas están ni de acuerdo ni en desacuerdo y el 4,0\% representado por 1 delegado expresa estar totalmente de acuerdo (tabla 9). Con esta información diagnóstica se tomó la decisión de establecer un plan y promoción de la ciudadanía para potenciar la eficacia del presupuesto participativo, lo cual guarda conexión con lo establecido por Pilay y Ugando (2020), que en su tesis realizada en Santo Domingo de Ecuador, plantean la necesidad de gestionar el presupuesto edil en aras de beneficiar a los sectores más necesitados que no participan en la toma de decisiones de ejecución de obras importantes, agua, desagüe, energía eléctrica, canalización, vías de comunicación, entre otras.

En esa misma tendencia se encuentra la investigación de Incil (2020) en Ascope de Trujillo Perú, en donde el nivel de participación civil es parcial en relación a las convocatorias ediles; no obstante, en cuanto participación en el presupuesto participativo osciló entre regular y deficiente. Para contrarrestar las deficiencias participativas, se propuso formar líderes juveniles, con capacidad de conocimiento, emprendimiento e innovación; así como gestionar los recursos y bienes para cumplir con las responsabilidades designadas. De la misma manera se propone establecer una política de incentivos que ayuden a fortalecer los derechos y las obligaciones participativas.

Sin embargo, esto se contrapone en parte por lo abordado por Asencio (2020), en su estudio en el distrito de Comas de Lima Perú, en donde se encontró que los ciudadanos se sienten desmotivados y disconformes por la actitud deshonesta de las autoridades y funcionarios públicos, en la priorización y ejecución de las obras en sectores que no la necesitan. Por ello, la respuesta a las convocatorias de la Comuna Edil es mínima y sin el número adecuado de personas, provocando una decisión unilateral de las autoridades, los cuales aprovechan la oportunidad para desviar el dinero en pago de coimas.

También se contrapone al estudio de Eslava \& Chacón (2018), en donde se registró que el presupuesto participativo en el contexto latinoamericano de Venezuela, Perú y Ecuador, presupuesto participativo edil es un importante instrumento de participación 
ciudadana en la gestión pública; no obstante, aún no se puede apreciar una verdadera democratización porque no se ha priorizado las demandas de los grupos más desfavorecidos. De allí la importancia de articular las políticas públicas nacionales con las regionales, los Presupuestos participativos para ajustarse a la realidad social y las necesidades básicas de la población.

En cuanto a los factores de la participación ciudadana que afectan la participación ciudadana en el manejo del presupuesto participativo edil, en la investigación doctoral se registraron que, el $44 \%$ representado por 11 delegados de autoridades locales manifestaron estar de acuerdo con el cumplimiento de estos ítems de dimensión, el 32\% representado por 8 encuestados están en desacuerdo y el $8,0 \%$ representado por 2 delegados expresaron estar totalmente de acuerdo, totalmente en desacuerdo y ni de acuerdo ni en desacuerdo respectivamente (tabla 10).

Lo anterior es completamente distinto a los hallazgos encontrados por Vilela et al. (2020), en un estudio a la comuna edil de Pueblo Libre de Lima, en donde el vecindario presenta un alto nivel de motivación personal y social en la toma de decisiones de la distribución presupuestal municipal, lo que permite fortalecer el modelo de la democracia participativa, y se logra verificar un alto sentido de justicia redistributiva.

Una situación totalmente distinta, ocurre con el estudio de los tesistas Rivera \& López (2019) desarrollada en Pasto de Colombia, donde se logró verificar la viabilidad y continuidad participativa del vecindario producto de las decisiones acertadas del gobierno edil y la coherencia de los objetivos de los movimientos sociales como actores políticos de alternancia municipal. Por tanto, las expectativas las necesidades, las aspiraciones, los reclamos ciudadanos y sus potencialidades se legitimaron por la cimentación de una participación auténtica y de una cultura política consistente, abierta y propositiva en el tiempo.

Adicionalmente, el hallazgo de la investigación parcialmente se diferencia de la investigación de Alvarado (2020) quien realizó una tesis en la región San Martín en Perú, encontrando una escasa participación del vecindario, provocando que los sectores vulnerables no se beneficien de las obras públicas de agua, desagüe, luz eléctrica, entre otros. Lo interesante del estudio se basa en la propuesta de la efectividad, la operatividad y el involucramiento de los vecinos a través de los balances e inspecciones de la gestión edil, acorde a las necesidades y expectativas; fortalecimiento de la capacidad técnica del gobierno y de los participantes con la finalidad de darle efectividad y eficiencia al gasto público.

Lo anterior guarda vinculación con el estudio de Moreno (2017) realizado en Huánuco Perú, donde se pudo comprobar una intervención significativa con el presupuesto participativo lo cual es importante para el desarrollo de Huánuco. Además, de acuerdo a 
los hallazgos, los vecinos se involucraron en la distribución presupuestal, mecanismos de rendición de cuentas, mecanismos de planificación y concertación y resultados presupuestales. Así mismo, se verificaron la efectividad de los principios rectores vinculados a la formulación política y beneficio de distribución social.

\section{Conclusiones}

- En relación al plan de fortalecimiento y promoción ciudadana para el proceso del presupuesto participativo, el estudio plantea la necesidad de establecer un conjunto de estrategias tales como realizar seguimientos a los proyectos de obras públicas, organizar reuniones periódicas, diseñar el reglamento, crear un canal de comunicación móvil, un plan de trabajo, aplicar auditorías y la creación de comités de seguimiento. Para ello, se plantea un conjunto de medios de verificación tales como las actas de reuniones, grabación audiovisual, informes de auditoría, resoluciones municipales e informes de monitoreo. De igual manera se plantea un cronograma acorde al planteamiento de las estrategias del plan las mismas que van desde una, dos meses, durante un mes, cada dos meses y durante todo un periodo de gobierno edil. Finalmente, se establece que recursos deben tomarse en cuenta entre ellos los libros de actas, el registro de asistencia, las fichas de verificación, el libro de auditorías y las fichas de registro.

- La investigación se relaciona en parte con la tesis de Alvarado (2020) quien propuso publicar los balances e inspecciones de la gestión edil, certificar un presupuesto participativo de acorde a las necesidades y expectativas; fortalecer la capacidad técnica del gobierno y de los participantes con la finalidad de darle efectividad y eficiencia al gasto público.

- Se debe indicar que teóricamente las variables participación ciudadana y presupuesto participativo edil, se sustentan en las teorías participativas propuestas por Ramírez (2015), importa aquí en la teoría de la cognición participativa, y la de los incentivos. En este caso, la primera depende de la cantidad de información que disponga para participar. Y la segunda busca influir en los incentivos colectivos, los sociales y los expresivos.

\section{Referencias Bibliográficas}

Alvarado, H. (2020). Modelo de gestión del presupuesto participativo para mejorar la calidad del gasto público en las municipalidades de la provincia del Huallaga, San Martin, año 2018. Perú: Trabajo especial de grado de la Universidad César Vallejo. 
Asencio, A. (2020). Conductas de la participación ciudadana en el presupuesto participativo del distrito de Comas, Lima 2019. Perú: Trabajo especial de grado de la Universidad César Vallejo.

Buele-Nugra, I., \& Vidueira, P. (2018). Presupuesto participativo: una revisión de la investigación científica y sus implicaciones democráticas del 2000 al 2016. Universitas, 0(28), 159-176.

Canto, R. (2017). Participación ciudadana, pluralismo y democracia. Tla-Melaua 10(41), 54-75.

Consejo Nacional de Ciencia, Tecnología e Innovación Tecnológica (CONCYTEC). (2020). Guía práctica para la formulación y ejecución de proyectos de investigación y desarrollo (I+D). Recuperado el 27 de enero de 2022, de http://www.untels.edu.pe/documentos/2020_09/2020.09.22_formuacionproyecto s.pdf

Eslava, R., \& Chacón, E. (2018). Presupuesto Participativo: un análisis en el contexto latinoamericano. Revista Gestión y Desarrollo Libre, 3(6), 1-12.

González, A., \& Soler, A. (2021). Nuevas miradas de los presupuestos participativos: los resultados de la participación desde la perspectiva política y técnica. OBETS. Revista de Ciencias Sociales, 16(1), 135-150.

Hernández, R., Fernández, C., \& Baptista, P. (2010). Metodología de la investigación.

Incil, D. (2020). Participación ciudadana en los presupuestos participativos de las municipalidades distritales de la Provincia de Ascope, 2019. Trabajo especial de grado de la Universidad César Vallejo.

Llona, M. (2017). Las formas de representación de la sociedad civil en los espacios de participación ciudadana: el Caso del presupuesto participativo en Villa el Salvador. Lima, Perú: Trabajo especial de grado de la Pontificia Universidad Católica del Perú para optar al título de Magister en Ciencia Política y Gobierno con mención en políticas y gestión Pública.

Maurice, S., Hao, C., \& Duncan, H. (2019). Strategies of Integrating Public Participation in Governance for Sustainable Development in Kenya. Public Policy and Administration Research, 9(7), 56-63.

Montecinos, E., \& Contreras, P. (2019). Participación ciudadana en la gestión pública: Una revisión sobre el estado actual. Revista Venezolana de Gerencia, 24(86), $341-362$. 
Moreno, A. (2017). Participación ciudadana y presupuesto participativo en las municipalidades distritales de la provincia de Huánuco, 2016. Trabajo especial de grado de la Universidad César Vallejo.

Núñez, L., \& Pedroza, R. (2019). Responsabilidad social y participación ciudadana en una municipalidad distrital de Lima Metropolitana. Revista Digital Gobierno y Gestión Pública, 6(2), 1-16.

Palella, S., \& Martins, F. (2010). Metodología de la investigación cuantitativa. Caracas, Venezuela: FEDUPEL, Fondo Editorial de la Universidad Pedagógica Experimental Libertador.

Pilay, F., \& Ugando, M. (2020). Presupuesto participativo en gobiernos autónomos descentralizados municipales de la provincia Santo Domingo de los Tsáchilas Ecuador. ECA Sinergia, 11(3), 137-151.

Príncipe, A., Tajada, A., \& La Cotera, J. (2021). Participación ciudadana y presupuesto participativo como una alternativa para una gobernanza efectiva para gobiernos locales en el Perú. Guayaquil-Ecuador: Compás.

Ramírez, J. (2015). Modelos de participación ciudadana. Una propuesta integradora. España: Trabajo especial de grado de la Universidad Carlos III de Madrid.

Rivera, F., \& López, L. (2019). El presupuesto participativo de Pasto: la dinámica participativa y las principales razones de la continuidad. Papel Político, 24(2).

Vilela, J., Fuster-Guillén, D. G., Guillén, P., Norabuena, R., \& Sánchez, S. (2020). Factores predominantes de la participación ciudadana en el proceso de presupuesto participativo. Revista Inclusiones 7.

\section{LCiencia}


El artículo que se publica es de exclusiva responsabilidad de los autores y no necesariamente reflejan el pensamiento de la Revista Alfa Publicaciones.

\section{Ciencia}

El artículo queda en propiedad de la revista y, por tanto, su publicación parcial y/o total en otro medio tiene que ser autorizado por el director de la Revista Alfa Publicaciones.
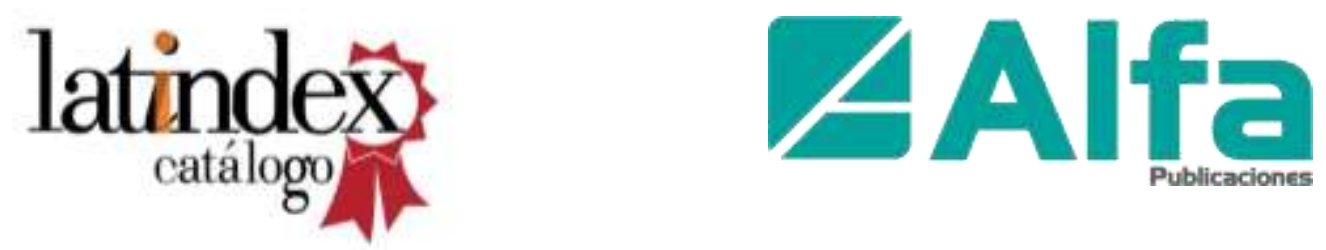

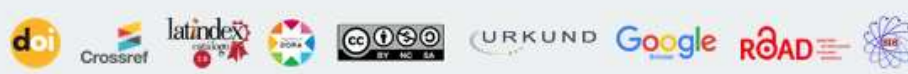
DLatinREV

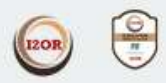

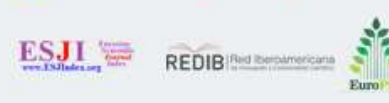

$\underbrace{}_{\text {wizdom.ai }} \mathrm{O}_{\text {OpenAIRE }}^{+}$

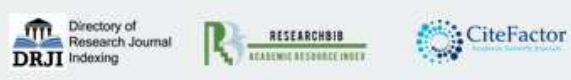

